\title{
BREVES REFLEXÕES SOBRE AS PRIMEIRAS ESCOLAS NORMAIS NO CONTEXTO EDUCACIONAL BRASILEIRO, NO SÉCULO XIX
}

\author{
Angela Maria Souza Martins \\ amsmartins@alternex.com.br \\ Universidade Federal do Estado do Rio de Janeiro - UNIRIO \\ NEB/NEPHEB
}

\section{RESUMO:}

Este trabalho investiga o processo de instituição das Escolas Normais brasileiras, no século XIX. Consideramos que a Escola Normal foi um ethos onde se desenvolveu uma cultura pedagógica, que resulta de representações e valores, responsáveis pela construção da identidade do professor primário brasileiro. Essa cultura pedagógica resulta do encontro da subjetividade com a objetividade, ou seja, decorre das condições sociais, econômicas, políticas e culturais das diferentes conjunturas históricas, mas também produz representações que instauram práticas e procedimentos pedagógicos que interferem na realidade social e histórica.

Palavras-Chave: Escola Normal, História das Instituições Escolares, Cultura Pedagógica.

\section{THOUGHTS OVER THE FIRST TEACHERS COLLEGES IN THE BRAZILIAN EDUCATIONAL CONTEXT IN THE XIXth CENTURY}

\begin{abstract}
:
This work investigates the institution process of the brazilians Teachers Colleges in the XIXth century. We consider the Teachers Colleges a educational ethos that developed a pedagogical culture that results from representations and values, responsible for the construction of the elementary teacher identity. This pedagogical culture comes from the fusion of the subjectivity with the objectivity, that is, it results from social, economical, political and cultural conditions of the different historical conjuntures and also produces representations that establish pedagogical pratices and procedures that interfere in the social and historical reality.
\end{abstract}

Keywords: Teachers Colleges, School History, Pedagogical Culture.

\section{Reflexões preliminares sobre a institucionalização da Escola Normal}

No mundo contemporâneo, a escola tornou-se uma das principais instâncias culturais, uma espécie de 'agência' com a tarefa de transmitir elementos culturais e reproduzir/transformar normas sociais e políticas. Há uma profunda relação entre educação e cultura. A esse respeito Forquin (1993, p. 10) esclarece:

Se toda educação é sempre educação de alguém por alguém, ela supõe sempre também necessariamente, a comunicação, a transmissão, a aquisição de alguma coisa: conhecimentos, competências, crenças hábitos, valores, que constituem o que se chama precisamente de 
"conteúdo" da educação [...] este conteúdo que se transmite na educação é sempre alguma coisa que nos precede, nos ultrapassa e nos institui enquanto sujeitos humanos, pode-se perfeitamente dar-lhe o nome cultura.

Desde o momento de sua institucionalização, a escola, enquanto instância reconhecida socialmente como 'locus' de produção e reprodução da cultura erudita, tornou o 'ethos' propício para o cultivo de uma cultura específica, a cultura pedagógica que resulta de representações, procedimentos e práticas educacionais que consolidam a postura do ser professor e do ser estudante. As representações veiculadas e fortalecidas no ambiente escolar criam identidades fundamentais para o reconhecimento profissional do professor, como servem para a construção de posturas do ser estudante. Isto porque as representações que construímos do mundo que nos cerca são simultaneamente subjetivas e objetivas, passivas e ativas, ou seja, refletem uma determinada conjuntura sócio-cultural, mas são também instauradoras de alguns procedimentos de nossas ações no cotidiano.

Lembramos que a escola frutifica no seio de uma determinada formação social tomando sua feição, mas produz por meio dos conteúdos pedagógicos e de suas práticas, uma cultura pedagógica responsável pela construção da identidade daqueles que a freqüentam.

As Escolas Normais, desde o momento de sua institucionalização, foram importantes 'agências' na mediação da cultura, ou melhor, instâncias responsáveis pela divulgação do saber, das normas e técnicas necessárias à formação dos professores. Consideramos a Escola Normal um 'ethos' que elabora uma cultura pedagógica para a formação do professor.

Como mencionamos anteriormente essa cultura pedagógica instalada nas Escolas Normais resulta do encontro da subjetividade com a objetividade numa determinada conjuntura histórica. Quem instaura essa cultura são estudantes e professores, sujeitos da ação cultural, que não agem somente pela subjetividade, porque sempre estão associados a grupos, seja no campo profissional como no campo artístico ou intelectual e, que também não são apenas mero reflexo das condições sociais e históricas, porque suas representações e práticas sociais interferem e constroem relações sociais. A cultura pedagógica decorre do homem síntese, definido por Gramsci (2001), do homem processo, síntese de múltiplas determinações.

Por isso, consideramos que a ambiência escolar expressa múltiplas facetas que transparecem no discurso de professores e estudantes, na aparência dos prédios escolares, nos currículos, nas atividades extracurriculares e no modo que estudantes e professores se relacionam.

Assim perguntamos: em que contexto sócio-político-cultural foram instauradas as Escolas Normais? Que tipo de cultura possibilitou o nascimento dessas escolas? Quais propósitos elas deviam servir? Quando surgiu a idéia contemporânea de Escola Normal? Qual era a cultura social e econômica instalada neste momento?

A Escola Normal laica surge cinco anos após a eclosão da Revolução Burguesa, na França. Ela teve vida breve, funcionou apenas de janeiro a maio de 1795. Mas neste curto espaço de tempo deixou para futuras experiências a sua concepção para formar professores. O caráter eminentemente científico foi o signo desta escola, por isso reconhecidos intelectuais da época deveriam estar entre seus mestres: Laplace, Lagrange e outros cientistas de renome criaram programas densos e complexos, guiados pela orientação da pesquisa científica. Os cursos foram estruturados em ciclos, como cada curso guardava autonomia, cada estudante, de acordo com seu interesse, podia organizar seu próprio plano de curso (VILLELA, 1990). 
A breve existência da escola Normal certamente deveu-se à mudança de orientação política da França pós-revolucionária. Não havia mais a preocupação de 'iluminar' a nação, por isso a educação elementar é posta em segundo plano porque o mais importante é formar as camadas dirigentes do Estado burguês. Na nova Constituição, a partir de 1795, os segmentos de ensino elementar e secundário passaram a ser pagos; suprimiu-se o salário do professor da escola elementar, que passou a receber uma pequena contribuição dos estudantes; reduziu-se o número de escolas secundárias; as meninas passaram a ser educadas pelos pais e estabelecimentos livres e promulgou-se a liberdade dos estabelecimentos particulares (VILLELA, 1990).

Acentuou-se, assim, a dualidade do ensino; permaneceu a distância entre educação elementar e a educação para a seleta camada que precisava ser ilustrada para efetivar o novo projeto político, cultural e econômico. Os professores, em sua maioria, continuaram mal qualificados e com remuneração insignificante.

Mas mesmo não se concretizando a promessa de: laicidade, gratuidade, estatalidade e universalização da educação, no final do século XVIII, este ideário permeará as discussões educacionais do século XIX. O contexto sócio-econômico-cultural do século XIX caracterizou-se pelo industrialismo ${ }^{1}$ (GRAMSCI, 2001), pela formação dos Estados e o triunfo da ciência. O industrialismo muda a face do trabalho e das cidades. O homem era considerado livre para vender sua força de trabalho, mas deveria se submeter às regras de trabalho e assalariamento da produção fabril. Para executar as suas tarefas devia ter instrução e saber dividir racionalmente sua tarefa com outros. Como a produção fabril concentrava-se em centros urbanos, devia aprender uma nova consciência de civilidade urbana, o que também era um processo educacional.

Esse aprendizado passava pelo domínio de alguns conhecimentos elementares da ciência, porque seus resultados possibilitavam um conhecimento verdadeiro da natureza e dos outros homens. A ciência facilitava a compreensão da evolução e do progresso humano, por isso os resultados científicos tornam-se imprescindíveis para a cultura do industrialismo, porque forneciam conhecimentos práticos para a vida.

Politicamente, no século XIX, está em curso o processo de formação dos Estados Nacionais, por isso cresce a necessidade de criar um sistema que pudesse nacionalizar, sistematizar e controlar a disseminação da instrução. Assim chegou o momento, devido às exigências sócio-econômico-culturais, de encontrar caminhos que pudessem ampliar a educação para uma grande parcela da população.

O século XIX foi marcado por um esforço significativo para efetivar os sistemas nacionais de educação. Desencadeou-se uma acirrada luta entre reacionários e liberais, conservadores e progressistas, para saber quem lideraria a hegemonia do processo educacional. Essa luta teve como pólos antagônicos, sobretudo, a Igreja e o Estado, mas este último venceu a disputa. Assim, proliferaram, no século XIX, os sistemas nacionais de educação e as leis sobre a instrução pública nos países europeus e americanos (LUZURIAGA, 1969). Nessa ambiência cresceu a importância do ensino elementar e da formação de professores. Propagaram-se, por toda a Europa e também nas Américas, as Escolas Normais.

\section{Contexto sócio-cultural brasileiro no século XIX}

As Escolas Normais começaram a aparecer no cenário sócio-cultural brasileiro a partir da terceira década do século XIX. Em 1835 em Niterói, em 1836 na Bahia, em 1845 no Ceará e, em 1846 em São Paulo. Até então, uma das principais mazelas da educação era 
a existência de professores improvisados, com péssima formação e mal remunerados. Não existiam projetos consistentes visando a ampliação da escolaridade elementar e, conseqüentemente, não havia uma proposta de qualificação do professor.

Mas o que provocou a proliferação de Escolas Normais no Brasil a partir da terceira década do século XIX? Neste período, o país passava por uma forte efervescência no campo político-cultural. D Pedro I tinha abdicado, o Brasil estava independente politicamente, mas precisava consolidar a soberania nacional, por meio de um Império que mostrasse uma face mais brasileira do que portuguesa. É um momento de intensa movimentação de idéias, quando confrontam-se o grupo da reação que pretendia uma espécie recolonização do Brasil e o grupo que lutava pela consolidação da autonomia brasileira. Eclodem, entre 1831 e 1840, vários levantes e insurreições, como a Balaiada no Maranhão, a Cabanagem no Pará, a Sabinada na Bahia e outros que lutavam pela descolonização efetiva do Brasil.

Caracterizando a efervescência desse período nos relata Faoro (1987, p. 317):

\begin{abstract}
Nas cidades, no Rio de Janeiro e na capital das províncias, os 'exaltados' comandam as ruas e os motins, poeira suspensa de camadas mal acomodadas à ordem imperial. Senhores de pasquins incendiários; ébrios com o vinho fora de safra da revolução Francesa entregam-se a todos os sonhos utópicos, antagonismos ao sistema social, desafiando os donos da riqueza. As praças e as esquinas geram desordeiros e anarquistas, sonhadores do nivelamento, em perigosa comunhão com soldados.
\end{abstract}

Nesse período, podíamos detectar três tendências político-sociais: os conservadores, os liberais exaltados e os liberais moderados (COSTA, 1985). Os conservadores representavam os interesses do primeiro império brasileiro, cujo representante era D.Pedro I. Defendiam o despotismo português, mas com a abdicação de D. Pedro I em 1831 e sua morte em 1834, esta tendência entra em decadência. Os liberais exaltados sonhavam com os ideais da Revolução Francesa, lutavam pela igualdade e liberdade, com uma efetiva aplicação desses ideais numa monarquia institucional ou numa assembléia popular. Esta facção começou a incomodar, tornando-se uma ameaça; temia-se uma revolta de caráter popular. Assim, ganharam expressão os liberais moderados, que propunham um liberalismo dentro da ordem para construir uma nação harmônica e equilibrada. $\mathrm{O}$ Ato adicional representava a vitória desse liberalismo com ordem, nos quais princípios liberais comungavam com princípios mais conservadores.

A partir do Ato Adicional de 1834, foi proposta a descentralização administrativa, sendo que a escolha dos presidentes das províncias deveria ser feita pelo governo central. Gradativamente, vai se construindo o império nacional de acordo com um liberalismo que não defendia mais o ideário revolucionário de 1789. Pretendia-se distribuir as "luzes" de modo qualitativo e não quantitativo. Apenas alguns poucos são considerados cidadãos ativos. De acordo com Faoro, "somente de $1 \%$ a 3\% do povo participa da formação da dita vontade nacional" (FAORO, 1987, p. 323). Mas mesmo de modo seletivo, a instrução era importante para "[...] romper as trevas que caracterizavam o passado colonial, superando a 'bárbarie' dos sertões e a 'desordem' das ruas, estabelecendo assim o primado da razão (VILLELA, 1990, p. 120). Pressuposto que respaldou o contexto no qual começaram a surgir as escolas de formação de professores.

Com a proposta de descentralização do ato institucional de 1834 , cada província tornou-se responsável pela organização dos seus sistemas de ensino primário e secundário. Assim, criou-se uma grande diversidade no incremento da instrução elementar e secundária, porque somente as províncias com recursos financeiros e projetos voltados 
para a implantação da instrução primária e secundária dariam um passo à frente na efetivação desses graus de ensino. Nas províncias de poucos recursos a instrução elementar e secundária permaneceu uma quimera.

\section{As Escolas Normais no contexto educacional brasileiro do século XIX}

Coube à província do Rio de Janeiro a primazia na implementação da primeira Escola Normal das Américas. Em 1835, no município de Niterói, promulgou-se a Lei n ${ }^{\circ} 10$ que organizou o ensino normal e estabeleceu as normas para aqueles que pretendiam se candidatar a escola Normal. Deveriam ser "cidadão brasileiro, maior de dezoito anos, com boa morigeração" e que soubesse ler e escrever (RIO DE JANEIRO, Lei n ${ }^{\circ} 10$, 4/04/1835, art. $4^{\circ}$ ). A boa morigeração relacionava-se à boa conduta, à moral e aos bons costumes. No artigo $6^{\circ}$ dessa lei encontramos de modo detalhado as providências que o candidato devia tomar:

Os que pretendem matricular-se dirigirão seu requerimento ao presidente da província, instruídos com a certidão de idade e a atestação de boa conduta, passada pelo juiz de Paz de seu domicílio: com despacho do mesmo presidente serão matriculados pelo diretor, se, pelo exame que deverá proceder, achar que possuem princípios suficientes de leitura e escrita (RIO DE JANEIRO, Lei n ${ }^{\circ} 10,4 / 04 / 1835$, art. $6^{\circ}$ ).

Chama-nos atenção o destaque dado a moral e à boa conduta, que deveria ser avalizada por um juiz de paz e as poucas exigências com relação à instrução: apenas saber ler e escrever. Havia uma preocupação explícita na formação de um professor que pudesse conduzir a mocidade segundo os princípios da ordem e boa conduta. Nas discussões parlamentares do Império, alguns deputados defendiam a necessidade de disseminar a ordem e a civilidade, "porque um professor imoral é a ruína da sociedade" ${ }^{2}$. A formação intelectual do professor não foi uma preocupação efetiva desse primeiro projeto de Escola Normal na província de Niterói. Na verdade, a intenção era a formação de professores que pudessem disseminar nas camadas populares a civilidade e a ordem, impregnar a sociedade com uma espécie de moral universal.

O professor oriundo da Escola Normal seria o veiculador de uma instrução elementar que forneceria:

Certas noções, certas práticas e sentimentos que devem ser gerais assim para as primeiras como para as classes superiores da sociedade. É essa instrução comum, essa identidade de hábitos intelectuais e morais, como bem diz um dos homens mais visto nessas matérias, o Sr Cousin, que constituem a unidade e a nacionalidade (Relatório do Presidente da Província do Rio de Janeiro, Aureliano de Souza Oliveira, apud VILLELA, 1990, p. 147)

A Escola Normal da província de Niterói deveria ser o centro formador de professores que teriam a missão de auxiliar na ordenação moral dos cidadãos. Essa preocupação parece ser uma constante em outros projetos educacionais de Escolas Normais no Brasil, no século XIX.

A Escola Normal de São Paulo, fundada em 1846, era conduzida por um único professor, Manuel José Chaves, catedrático de Filosofia e Moral. A formação acadêmica 
desse professor provavelmente deve ter sido o fio condutor do curso ministrado nessa instituição.

Na Reforma do Ministro do Império, Luiz Pedreira do Couto Ferraz, apareciam exigências rigorosas para o exercício do magistério público e particular. O professor deveria apresentar provas de moralidade e capacidade para ocupar a cadeira de professor.

Quanto ao elemento feminino que se dispunha educar, as exigências morais atingiam a vida privada.

\begin{abstract}
As professoras devem exibir, de mais, se casadas, a certidão do seu casamento; se viúvas, a do óbito de seus maridos; e se viverem separadas destes a pública sentença que julgar a separação, para se avaliar o motivo que a originou.

As solteiras só poderão exercer o magistério público tendo 25 anos completos de idade, salvo se ensinarem na casa dos pais e estes forem de reconhecida moralidade (Lei Couto Ferraz. Decreto $\mathrm{n}^{\circ} 133$, de $17 / 02 / 1854$, art $16^{\circ}$ )
\end{abstract}

Além de atestados, folhas corridas e certidões, o professor deveria apresentar um vestuário decente, porque a sua aparência também atestava a sua boa conduta e moralidade. Assim, até praticamente o final do século XIX, a missão do professor deveria ser a condução moral, sobretudo das camadas populares. Intenção, que desde a primeira metade do século XIX, estava explícita nos documentos de alguns dirigentes de província. No Relatório de 1839, o Presidente da Província do Rio de Janeiro, Paulino José Soares de Souza sugeria:

[...] é preciso portanto juntar à instrução primária a educação e educar o povo, inspirar-lhe sentimentos de religião e moral, melhorando-lhe assim pouco a pouco os costumes (Relatório do Presidente da Província do Rio de Janeiro, José Paulino Soares de Souza, apud VILLELA, 1990, p. 155)

Concordamos com a hipótese de Villela (1990) que a Escola Normal brasileira, no século XIX, tinha como função formar o 'sacerdote laico', o 'disseminador das luzes' que ordenaria moralmente as camadas populares. Villela (1990) reconhece que a estrutura educacional brasileira não assimilou propriamente a proposta francesa de $\mathrm{Guizot}^{3}$, ela adaptou/modificou, de acordo com a sua conjuntura sócio-político cultural, aquela proposta.

A questão da ordem, da moralização disseminou-se naquele momento histórico brasileiro, porque o Brasil, de 1817 a 1888, estava sendo sacudido por vários levantes e insurreições de caráter político-social ${ }^{4}$. O contexto sócio-cultural brasileiro passava por transformações significativas: a disseminação de idéias liberais e republicanas; a eclosão de vários movimentos abolicionistas e a discussão nas academias das idéias evolucionistas e positivistas.

Essa efervescência político-cultural possibilitou a ampliação da discussão sobre a escola pública elementar e a importância das Escolas Normais para a qualificação do professor. Nesse contexto, começaram a proliferar as Escolas Normais brasileiras, sendo a escola Normal de Niterói, apesar de sua breve existência de 16 anos (1835-1851), um marco importante no processo de institucionalização e legitimação da escola Normal como 'ethos' para formação do professor, mormente do ensino elementar.

A partir de 1870, notamos duas medidas que caracterizaram uma mudança cultural nos rumos da educação: a exigência de prédios próprios para a instalação de escolas e a definição da Escola Normal como o 'locus' mais adequado para a formar professores mais 
qualificados (AZEVEDO, 1953), porque não se podia admitir professores improvisados e desqualificados.

De acordo com esta nova concepção cultural, apareceram cinco Escolas Normais em Minas Gerais: em 1872, uma na capital e uma de Campanha; em 1879, em Diamantina e no ano de 1880, em Montes Claros e Paracatu. A reforma da instrução primária de 1873 da província do Espírito Santo sugeriu a criação de uma Escola Normal. Em 1874, foram criadas as Escolas Normais da província do Rio Grande do Norte e do Município Neutro do Rio de Janeiro e, no ano 1882, a da província do Amazonas. Mesmo que várias dessas escolas tenham tido vida efêmera, a proliferação delas indicou uma mudança cultural quanto à formação do educador.

Não podemos deixar de destacar que foi importante a consolidação do projeto educacional da Escola Normal do Município Neutro do Rio de Janeiro, em especial devido a importância política deste município. A Escola Normal Livre foi a primeira experiência no Município Neutro do Rio de Janeiro, no sentido de formar professores mais qualificados. Funcionou de março de 1874 a 20 de dezembro de 1875; era particular, mas subsidiada pelo governo, por isso seu ensino era gratuito. Em 1876, por meio do decreto $\mathrm{n}^{\circ}$ 6.379, o Ministro do Império, José Bento da Cunha Figueiredo, tentou instalar Escolas Normais públicas e estatais: uma, em regime de externato, para professores e outra, em regime de internato, para professoras primárias. Mas a Escola Normal pública e gratuita concretizou-se somente em 1880.

Por meio do decreto $\mathrm{n}^{\circ} 8.025$ de 16 de março de 1881 ficou estabelecido que:

Artigo $1^{\circ}$ : A Escola Normal tem por fim preparar professores primários de $1^{\circ}$ e $2^{\circ}$ graus: o ensino nela distribuído será gratuito, destinado a ambos os sexos, e compreenderá dois cursos - o de ciências e letras e o de artes.

Artigo 2०: O curso de Ciências e Letras se comporá das seguintes matérias: Instrução Religiosa, Português, Francês, Matemática Elementar, Corografia e História do Brasil. Cosmografia, Geografia e História Geral, Elementos de Mecânica e Astronomia, Ciências Físicas, Ciências Biológicas, Lógica e Direito Natural e Público. Economia Social e Doméstica, Pedagogia e Metodologia.

Artigo $3^{\circ}$ : O curso de Artes abrangerá as seguintes disciplinas: Caligrafia e Desenho Linear, Música Vocal, Ginástica, Trabalhos de Agulha (para alunas) (DECRETO n ${ }^{\circ} 8.025,16 / 03 / 1881$, art. $1^{\circ}, 2^{\circ}$ e $3^{\circ}$ ).

Esses cursos eram ministrados em quatro séries. Observamos uma tentativa no elenco de matérias do curso de Ciências e Letras de conceder ao professor uma formação de caráter científico. Tal intenção ficou explícita na proposta de seu diretor interino, o bacharel Benjamin Constant: "difundir por todas as classes de nossa sociedade uma larga e sólida instrução que inicie o cidadão nos grandes e úteis resultados nos domínios da atividade científica, industrial e social, dando-lhe noções claras, seguras e bem coordenadas sobre as coisas e sobre o homem para esclarecer-lhe a inteligência e dirigir sua conduta" (Discurso de Benjamin Constant, apud, SILVEIRA, 1954, p.10).

Nesse discurso de Benjamin Constant encontramos alguns subsídios para compreender o tipo de cultura que deveria, a partir de então, impregnar a formação do educador. Uma cultura baseada numa visão científica, mas de acordo com uma postura que começava a ser gestada, muito lentamente, no Brasil: a visão de homem urbano, que tinha como parâmetro o 'industrialismo'. O homem, a partir de então, devia aprender a se conduzir 'bem' nesse novo universo cultural. Tal intenção pode ser corroborada com as 
exigências que deviam ser cumpridas para ingressar na Escola Normal. Além dos documentos formais como certidão de idade, que comprovasse a idade de 16 anos para rapazes e 15 para moças e a aprovação num exame de admissão que medisse a capacidade de leitura, escrita, noções de gramática e de aritmética, o candidato deveria apresentar um atestado de moralidade referendado pelo pároco ou padre local ou por duas pessoas conceituadas da Corte.

Idoneidade moral e formação científica marcaram a primeira proposta de ensino público e gratuito da escola Normal do Município Neutro do Rio de Janeiro. Começava, mesmo que de modo incipiente, uma cultura escolar que devia formar professores que passassem às diferentes camadas sociais, "[...] preceitos da moral cristã, com máximas da higiene corporal, com as regras da disciplina escolar, evitando que, entre elas, medrassem preconceitos oriundos da posição social, enfim guiá-las, para que se transformassem em servidores leais da Pátria brasileira (SILVEIRA, 1954, p. 19)".

Em 1888, houve uma mudança na orientação curricular da escola Normal do Município da Corte do Rio de Janeiro, o ensino passou a ser ministrado em três séries devendo, em todas elas, ser ministrada a Instrução Moral e Cívica (SILVEIRA, 1954). Na Reforma Benjamin Constant, em 1890, apareceu também uma disciplina para a formação cívica e moral: Sociologia e Moral.

Preocupação que persistiu no século XX. Em 1929, na sua obra sobre Metodologia da Educação Moral, Alba Cãnizares esclarece: "a obra precípua da escola é a formação moral do povo. E não é obra que se processe sem alta capacidade docente" (CÃNIZARES, apud, ACCÁCIO, 1993, p. 41).

A partir do final do século XIX e início do século XX, observamos uma dupla preocupação no processo de formação do professor: a profissionalização e uma nova conformação moral e social daqueles que pretendiam ensinar. Essa preocupação permeou a trajetória histórica da Escola Normal, nas principais cidades brasileiras. A busca de um profissional da educação de acordo com os novos princípios de urbanidade, um civilizador, estava presente nas discussões e reformas educacionais do final do século XIX e início do século XX. Era preciso formar um novo tipo de educador, num 'locus' específico, a Escola Normal deveria possuir instalações apropriadas à sua missão, de acordo com os princípios morais e científicos que pudessem 'conformar' o homem moderno e civilizado.

\section{Considerações Finais}

Acreditamos que o mundo cultural é povoado de representações e percepções da realidade social, que produzem estratégias e práticas que podem legitimar um projeto e justificar condutas e escolhas. Partindo desse pressuposto constatamos que, desde o momento de sua institucionalização até o século XX, as Escolas Normais foram o principal 'ethos', onde foram criadas as condições culturais para a formação do professor do primeiro segmento da Educação Básica.

Esse 'ethos' não deve ser visto somente como um reflexo das condições sóciohistóricas que o instauraram, mas também como criador e consolidador de uma 'cultura pedagógica' necessária à formação do educador. No século XIX, a cultura pedagógica instalada nas Escolas Normais considerou que o professor seria a pessoa que deveria cumprir a missão moral e educacional de levar o esclarecimento para a população ignorante, aquele que iluminaria as mentes e possibilitaria a transmissão do saber a todos. $\mathrm{O}$ professor passou a ser representado como alguém que poderia facilitar e ajudar o desenvolvimento e o progresso de uma nação. Por isso, ele deveria ser um profissional formado dentro dos princípios morais e portador de uma sólida erudição e o local por 
excelência para esta formação seria a Escola Normal. Consideramos que a Escola Normal nos séculos XIX e XX teve um papel fundamental na institucionalização de uma determinada cultura para formar o professor. Para deixar uma reflexão final, pensemos nesta afirmação de Gramsci, a cultura é uma "[...] concepção da vida e do homem, uma 'religião laica', uma filosofia que tenha se transformado precisamente em 'cultura', isto é, que tenha gerado uma ética, um modo de viver, uma conduta civil e individual" (GRAMSCI, 1978, p. 4).

\section{Referências}

ACCÁCIO, Liéte de Oliveira. Instituto de Educação do Rio de Janeiro: a história da formação do professor primário. Dissertação (Mestrado em Educação) - Universidade Federal do Rio de Janeiro, Rio de Janeiro, 1993.

AZEVEDO, Fernando de. A cultura brasileira. São Paulo: Melhoramentos, 1953.

BRASIL. Lei Couto Ferraz. Decreto ${ }^{\circ}$ 133, de 17 de fevereiro de 1854.

BRASIL. Decreto Lei n ${ }^{\circ}$ 8.025, de 16 de março de 1881.

COSTA, Emília Viotti. Da Monarquia à República: momentos decisivos. São Paulo: Brasiliense, 1985.

FAORO, Raymundo. Os Donos do Poder. Rio de Janeiro: Ed. Globo, 1987. v.1

FORQUIN, Jean Claude. Escola e Cultura: as bases epistemológicas do conhecimento escolar. Porto Alegre, RS: Artes Médicas, 1993.

GRAMSCI, Antonio. Literatura e vida nacional. Rio de Janeiro: Civilização Brasileira, 1978.

Cadernos do Cárcere. Rio de Janeiro: Civilização Brasileira, 2001.

LUZURIAGA, Lorenzo. História da educação e da Pedagogia. São Paulo: Companhia Editora Nacional, 1969.

RIO DE JANEIRO. Lei ${ }^{\circ} 10$, de 4 de abril de 1835 . Dispõe sobre a organização do ensino normal e estabelece as normas de ingresso nesta modalidade de ensino. Rio de Janeiro, 1835.

SILVEIRA, Alfredo Baltazar. História do Instituto de Educação. Rio de Janeiro: Prefeitura do Distrito Federal, 1954.

VILLELA, Heloisa de Oliveira Santos. A primeira Escola Normal do Brasil: uma contribuição à história da formação de professores. Dissertação (Mestrado em Educação) Universidade Federal Fluminense, Niterói, 1990.

NOTAS:

\footnotetext{
${ }^{1} \mathrm{O}$ termo industrialismo é usado de acordo com a concepção gramsciana, ou seja, um novo tipo de cultura criado a partir do trabalho industrial que transforma a sociedade, conseqüentemente, a escola e os métodos pedagógicos.
} 
${ }^{2}$ Trecho do discurso do deputado Augusto Xavier de Carvalho apud Villela. VILLELA, Heloisa de Oliveira Santos. A primeira Escola Normal do Brasil: uma contribuição à história da formação de professores. Dissertação (Mestrado em Educação) - Universidade Federal Fluminense, Niterói, 1990. p.127

${ }^{3}$ De 1830 a 1848, instalou-se na França a 'monarquia de julho', de espírito liberal, promovendo através de seu Ministro Guizot mudanças substanciais no ensino elementar e normal. Nesse período a França chegou a ter 77 Escolas Normais. Guizot inspirou-se no filósofo Victor Cousin para fundamentar suas propostas educacionais. Ele sugeriu que cada comuna criasse uma escola elementar e uma Escola Normal. O professor, para exercer o magistério, precisava de um comprovante de idoneidade moral e de um certificado de habilitação, obtido através de exames nos departamentos. Para melhorar prática e teoricamente o exercício da docência distribuía-se manuais com conselhos práticos e teorias pedagógicas. Para Guizot o professor deveria ter uma sólida formação moral e religiosa e o sistema de ensino devia estar sob a vigilância constante do Estado. O professor tinha a missão de formar o povo para uma vida útil e moral. Por isso, ele deveria ser o 'sacerdote laico'.

${ }^{4}$ Revoltas ocorridas entre 1871 e 1888: Insurreição de 1817 no Nordeste; de 1831 a 1840: Sabinada, na Bahia; Balaiada, no Maranhão; Farroupilha, no Rio Grande do Sul; Cabanagem, no Pará. Revoluções liberais de 1842 (Minas Gerais e São Paulo); a Revolução Praieira (1848); as Guerras no Prata (década de 1850) e a Guerra do Paraguai (1865-1870). Além dessas revoltas, tivemos vários movimentos em prol da abolição da escravatura.

Artigo recebido em: 30/08/09

Aprovado para publicação em: 04/09/2009 